\title{
Regulation of $\mathrm{PI} 4,5 \mathrm{P}_{2}$ synthesis by nuclear- cytoplasmic shuttling of the Mss4 lipid kinase
}

\author{
Anjon Audhya and Scott D.Emr ${ }^{\mathbf{1}}$ \\ Department of Cellular and Molecular Medicine and The Howard \\ Hughes Medical Institute, University of California, San Diego, \\ School of Medicine, La Jolla, CA 92093-0668, USA \\ ${ }^{1}$ Corresponding author \\ e-mail: semr@ucsd.edu
}

The essential phospholipid PI4,5 $\mathrm{P}_{2}$ is generated by a well conserved PI4P 5-kinase, Mss4, in yeast. Balanced production and turnover of $\mathrm{PI} 4,5 \mathrm{P}_{2}$ is important for normal organization of the actin cytoskeleton and cell viability. Previous studies have shown that multiple PI phosphatases can regulate $\mathrm{PI4,5P_{2 }}$ levels. We report a new, unexpected regulatory mechanism for $\mathrm{PI} 4,5 \mathrm{P}_{2}$ homeostasis, directed by nuclearcytoplasmic shuttling of the lipid kinase. We show that Mss4 is a phosphoprotein, which contains a functional nuclear localization signal (NLS) and can shuttle between the cytoplasm and the nucleus. Temperatureconditional mss 4 cells that accumulate Mss4 protein in the nucleus exhibit reduced levels of $\mathrm{PI} 4,5 \mathrm{P}_{2}$, depolarization of the actin cytoskeleton and a block in Mss4 phosphorylation, suggesting an essential role for phosphorylated Mss4 at the plasma membrane. Through the isolation of gene dosage-dependent suppressors of mss4 mutants, we identified Bcp1, a protein enriched in the nucleus, which is required for Mss4 nuclear export and is related to the mammalian BRCA2-interacting protein BCCIP. Together, these studies suggest a new mechanism for lipid kinase regulation through regulated nuclear-cytoplasmic shuttling.

Keywords: actin/BRCA2/nuclear transport/

phosphoinositide/phosphorylation

\section{Introduction}

Regulated production and turnover of different phospholipids is essential to a variety of distinct cellular processes. In particular, derivatives of phosphatidylinositol, collectively known as phosphoinositides, have been shown to be important for multiple functions, including cytoskeleton organization, vesicle trafficking, cell proliferation and cell growth (Fruman et al., 1998; Martin, 1998). Historically, the major phosphoinositide PI4,5 $\mathrm{P}_{2}$ has been mainly associated with the generation of two essential second messengers, inositol 1,4,5-triphosphate and diacylglycerol, required in a variety of cellular responses (Berridge and Irvine, 1984). However, recent studies have underscored the importance of PI4,5 $\mathrm{P}_{2}$, directly in the maintenance of actin cytoskeleton organization, as well as in normal endocytosis and synaptic vesicle recycling (Takenawa and Itoh, 2001). Importantly, both impaired synthesis and inappropriate accumulation of $\mathrm{PI} 4,5 \mathrm{P}_{2}$ have been found to have a negative impact on these processes.

In budding yeast, a single essential gene MSS4 encodes the total cellular PI4P 5-kinase activity. MSS4 was initially identified in a screen for multicopy suppressors of stt4 mutant cells that exhibited reduced PI4-kinase activity (Yoshida et al., 1994). Later, Mss4 was shown to localize to the plasma membrane (Homma et al., 1998), where it directed $\mathrm{PI} 4,5 \mathrm{P}_{2}$ synthesis, essential for maintenance of actin cytoskeleton organization and endocytosis (Desrivières et al., 1998; Audhya and Emr, 2002). Regulation of the actin cytoskeleton by Mss4-derived $\mathrm{PI} 4,5 \mathrm{P}_{2}$ is at least in part mediated through the recruitment/activation of a pleckstrin homology domain containing guanine nucleotide exchange factor for the Rho1 GTPase, previously shown to be essential for normal actin organization (Delley and Hall, 1999; Audhya and Emr, 2002). Interestingly, accumulation of PI $4,5 \mathrm{P}_{2}$ caused by the deletion of the $\mathrm{PI} 4,5 \mathrm{P}_{2}$-specific synaptojanin-like phosphatase Sj11 (also called Inp51) was shown to inappropriately upregulate the activity of a Rhol effector Pkc1, indicating the importance of proper $\mathrm{PI} 4,5 \mathrm{P}_{2}$ homeostasis (Audhya and Emr, 2002). Moreover, deletion of multiple synaptojanin-like phosphatases is lethal (Srinivasan et al., 1997; Stolz et al., 1998), and a temperature-sensitive $s j l 1 \Delta /$ sjl2ts $/ s j l 3 \Delta$ strain shows defects in actin organization similar to that observed in cells expressing a hyperactivated form of Rhol (Delley and Hall, 1999; Stefan et al., 2002). Thus, proper control of cellular PI4,5 $\mathrm{P}_{2}$ levels is absolutely essential for normal cell function and viability.

To initiate characterization of regulatory mechanisms governing the Mss4 lipid kinase, we closely examined the localization of Mss4 in both wild-type and mss 4 mutant cells. We found that Mss4 contains a functional nuclear localization signal (NLS). Interestingly, cells expressing a mutant form of Mss4 that becomes trapped in the nucleus but harbors no mutations in its kinase domain showed a defect in $\mathrm{PI} 4,5 \mathrm{P}_{2}$ synthesis, suggesting that nuclear shuttling may regulate $\mathrm{PI} 4,5 \mathrm{P}_{2}$ production at the plasma membrane. We also found that Mss4 was phosphorylated at the plasma membrane by casein kinase I, and that phosphorylation was important for stable association of Mss4 with the plasma membrane. Finally, in a screen for gene dosage suppressors of $m s s 4^{\text {ts }}$ mutant cells, we isolated a new essential nuclear protein involved in nuclear shuttling of Mss4, which also was important for normal $\mathrm{PI} 4,5 \mathrm{P}_{2}$ production. Together, these data show that the essential function of Mss4 resides at the plasma membrane, and that levels of PI4,5 $\mathrm{P}_{2}$ synthesis can be controlled by a new mechanism directly affecting the localization of the PI4P 5-kinase. 

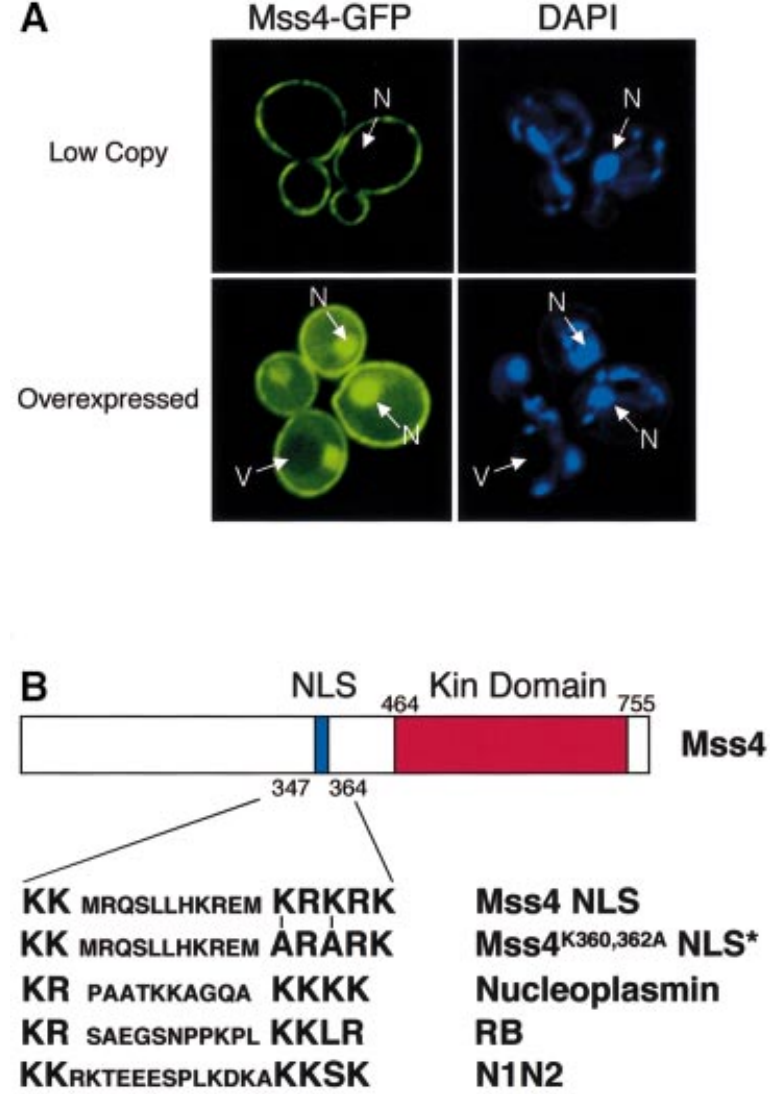

Fig. 1. Mss4 is localized to the plasma membrane and the nucleus. (A) $m s s 4 \Delta$ cells carrying pRS416 MSS4-GFP (Low Copy) or pRS426 MSS4-GFP (Overexpressed) were visualized by fluorescence microscopy. DAPI-stained DNA is shown on the right. Pictures are representative of $>150$ cells observed. Nuclei $(\mathrm{N})$ and vacuoles $(\mathrm{V})$ are indicated by arrows. (B) Cartoon showing the structure of Mss4, including the sequence of its potential bipartite NLS, a mutated form of the NLS (NLS*), and an alignment with other previously characterized NLSs.

\section{Results}

\section{Mss4 contains a functional NLS}

Mss4 is a well conserved PI4P 5-kinase that has been shown to localize to the plasma membrane (Homma et al., 1998) and function in the maintenance of normal actin cytoskeleton organization, at least in part through activation of a Rho-type GTPase, in the yeast Saccharomyces cerevisiae (Desrivières et al., 1998; Audhya and Emr, 2002). To further investigate the localization of Mss4, we first tagged the endogenous copy of MSS4 with a sequence encoding green fluorescent protein (GFP). The fusion protein was functional as assayed by normal growth of the resulting strain and normal production of $\mathrm{PI} 4,5 \mathrm{P}_{2}$ as compared with wild-type cells (data not shown). Fluorescence microscopy revealed plasma membrane localization of Mss4-GFP, sometimes enriched on punctate, cortical structures, but upon overexpression of the fusion protein, Mss4 was also found to be present in the nucleus (Figure 1A). Previous studies have shown that nuclear transport through nuclear pore complexes (NPCs) is highly selective and tightly regulated (Mattaj and Englmeier, 1998). Thus it is unlikely that simple overexpression of Mss4 allowed for passive diffusion through NPCs, especially due to the size restriction of the nuclear pore.

Sequence analysis of Mss4 revealed a putative bipartite NLS upstream of the kinase domain, similar to previously characterized bipartite NLSs found in bona fide nuclear proteins including nucleoplasmin, $\mathrm{Rb}$ and N1N2 (Figure 1B). To test whether this domain of Mss4 could function as a NLS in vivo, we used a competition assay in which a GFP reporter was fused in tandem to both the Mss4 NLS and to the leucine-rich NES of PKI, which has previously been shown to contain a potent, functional export signal recognized by the Crm1 nuclear protein export factor (Stade et al., 1997). This construct (Mss4-NLS-NES-GFP) was introduced into $\mathrm{crm} 1 \Delta$ cells harboring a mutant form of $\mathrm{Crm} 1\left(\mathrm{crm} \mathrm{I}^{\mathrm{T} 539 \mathrm{C}}\right)$, which is sensitive to the drug leptomycin (Neville and Rosbash, 1999). In the absence of leptomycin, the Mss4-NLS-NESGFP fusion was found mainly in the cytoplasm (Figure 2). Similarly, GFP alone and the previously characterized SV40-NLS fused to PKI-NES-GFP (Taura et al., 1997) were also observed in the cytoplasm. However, in the presence of leptomycin, both the SV40-NLS-NES-GFP and Mss4-NLS-NES-GFP fusion proteins quickly accumulated within the nucleus $(<15 \mathrm{~min})$, while the localization of GFP was not affected, indicating that the Mss4 NLS is functional in vivo.

Previous studies have shown that many NLS peptides contain critical basic amino acids important for binding to soluble transport factors (Dingwall and Laskey, 1991). To test for this requirement in the Mss4 NLS, we used sitedirected mutagenesis to change two lysines into alanines (K360A, K362A), resulting in the Mss4-NLS*-NES-GFP mutant fusion protein. Strikingly, this mutated NLS fusion protein failed to accumulate in the nucleus in the presence of leptomycin. Instead, it remained mostly cytoplasmic, sometimes associating with punctate structures (Figure 2). Together, these studies indicate that Mss4 contains a functional NLS, capable of regulated nuclear import.

\section{Identification of mutant mss4 alleles that accumulate Mss4 in the nucleus}

The steady-state localization of Mss4 at the plasma membrane under standard laboratory growth conditions suggests an asymmetry in the rate of Mss4 nuclear import and its export. In addition, previous studies have suggested an essential role for PI4,5 $\mathrm{P}_{2}$ synthesis at the plasma membrane for proper organization of the actin cytoskeleton (Desrivières et al., 1998; Homma et al., 1998; Audhya and Emr, 2002). We therefore reasoned that we may be able to isolate mutant forms of Mss4 that accumulate in the nucleus by generating temperature-conditional alleles of $M S S 4-G F P$, followed by a secondary fluorescence-based screen for mutants that failed to localize properly. Two different classes of temperature-sensitive mutants were isolated. The first class expressed Mss4 on the plasma membrane at the permissive temperature, but exhibited strong nuclear localization after a 45 -min shift to elevated temperature (Figure 3A). The second class of mutants exhibited Mss4 localization to the plasma membrane independent of temperature. Representative alleles for each class were chosen for further study, mss4-1 (class I) 


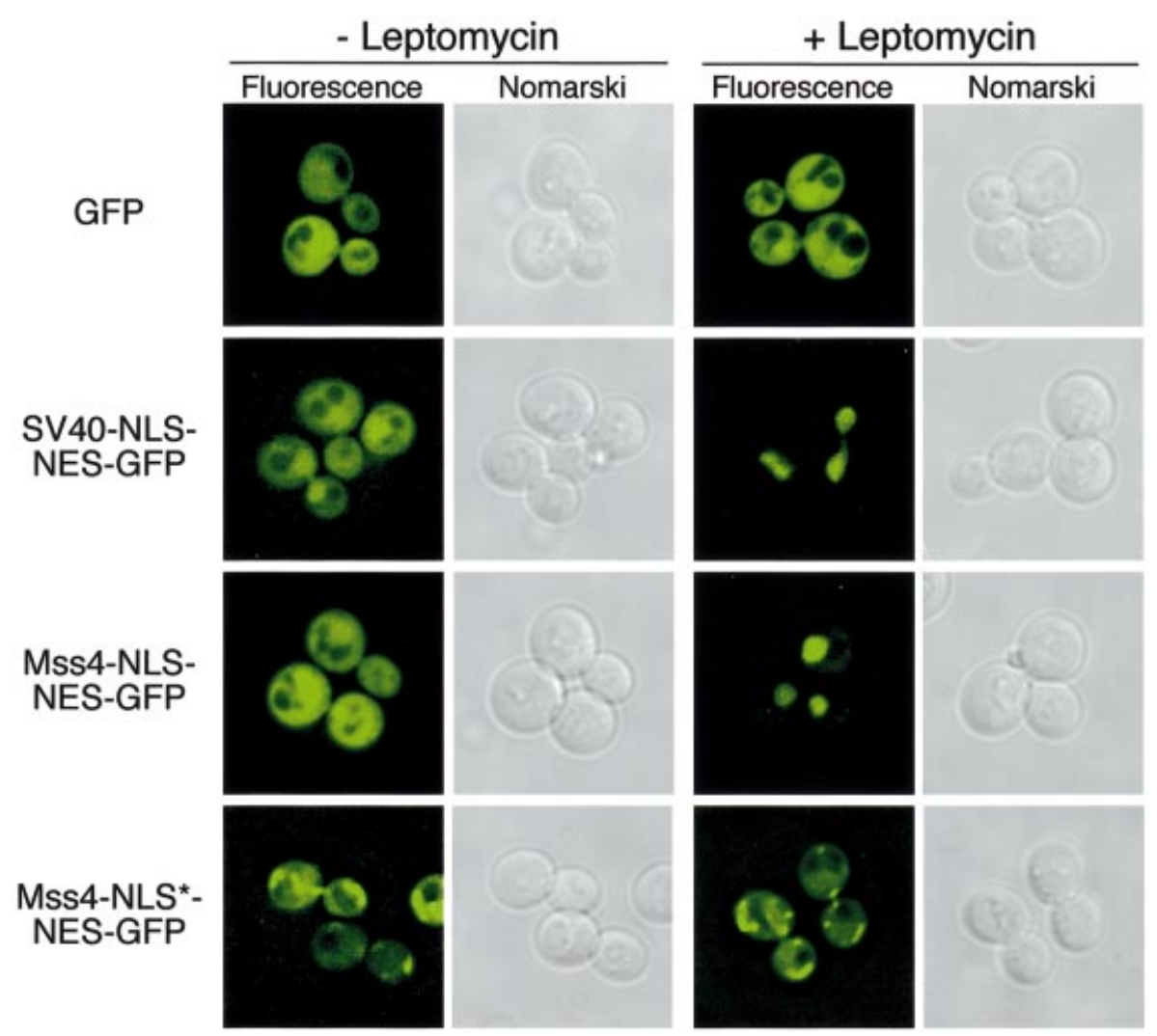

Fig. 2. Mss4 harbors a functional nuclear localization signal. $\mathrm{crm} 1 \Delta$ cells expressing $\mathrm{crm} \mathrm{l}^{\mathrm{T} 539 \mathrm{C}}$ were transformed with constructs expressing GFP, SV40-NLS-NES-GFP, Mss4-NLS-NES-GFP or Mss4-NLS*-NES-GFP, and visualized by fluorescence microscopy in the presence or absence of $100 \mathrm{ng} / \mathrm{ml}$ leptomycin. Pictures are representative of $>150$ cells observed.
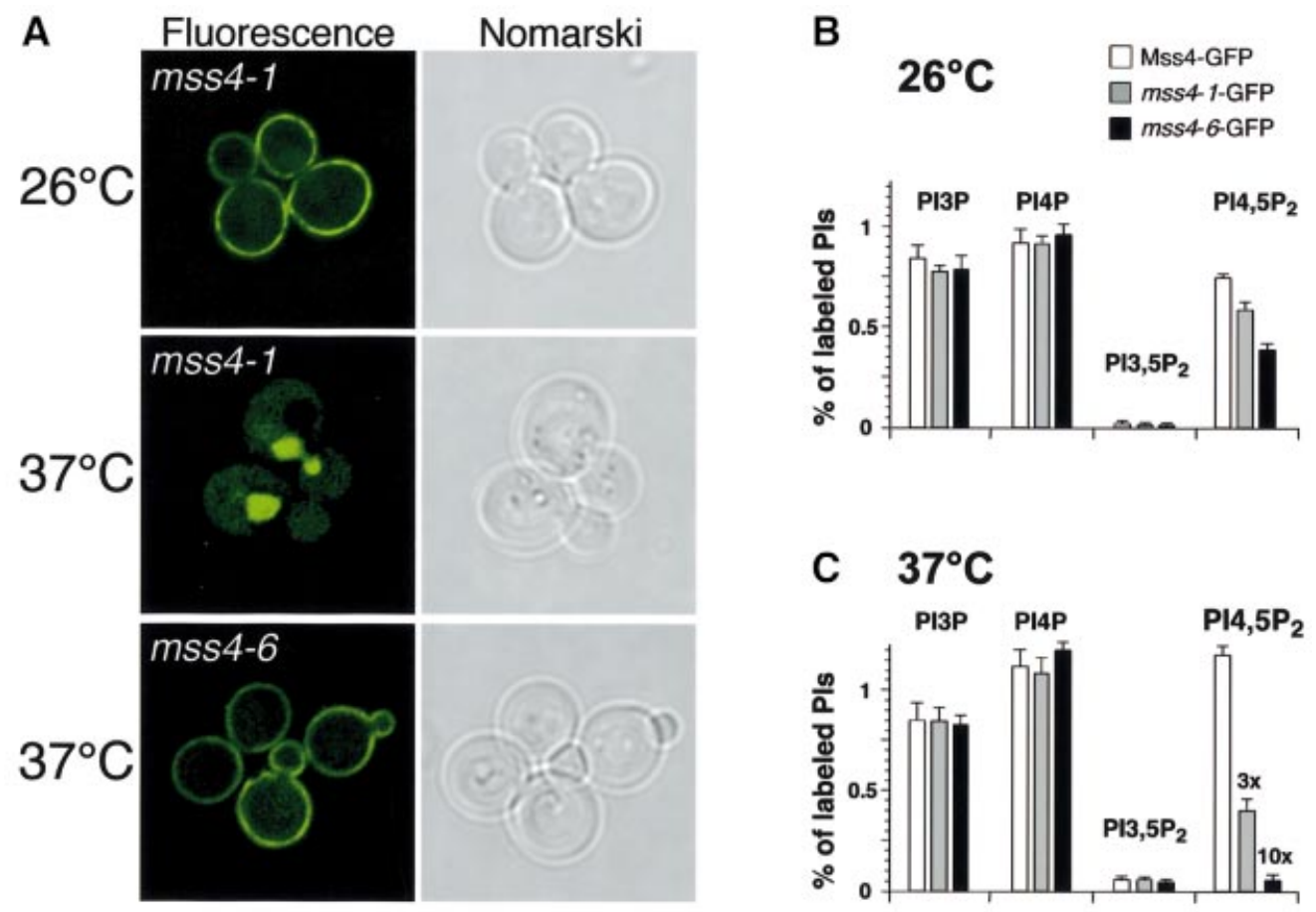

Fig. 3. Inappropriate nuclear import of Mss 4 results in a defect in $\mathrm{PI} 4,5 \mathrm{P}_{2}$ production. (A) $m s s 4 \Delta$ cells expressing $m s s 4-1-G F P$ or $m s s 4-6-G F P$ were visualized by fluorescence microscopy at the temperatures indicated. (B and C) Phosphoinositide levels in $m s s 4 \Delta$ cells expressing MSS4-GFP, mss4-1-GFP or mss4-6-GFP. 

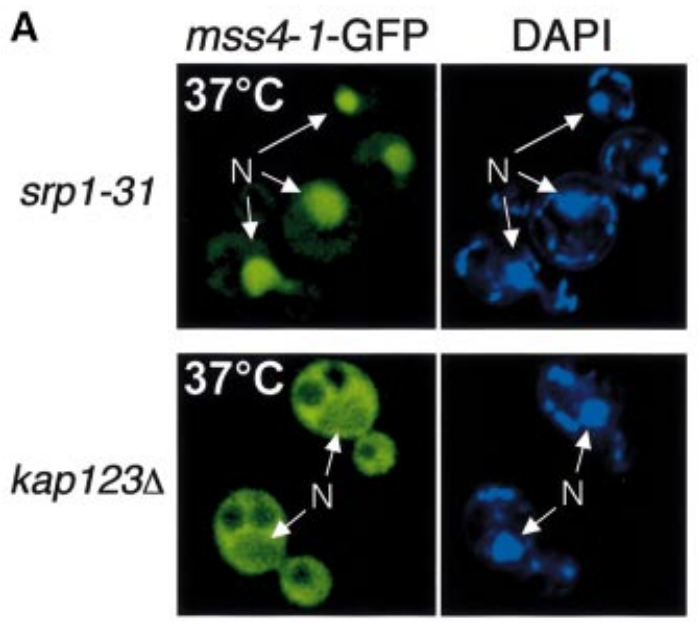

B
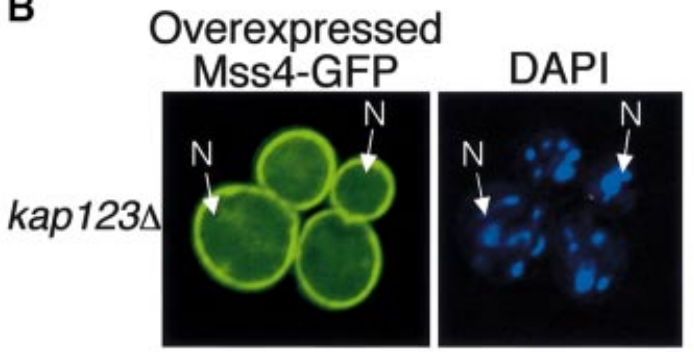

C

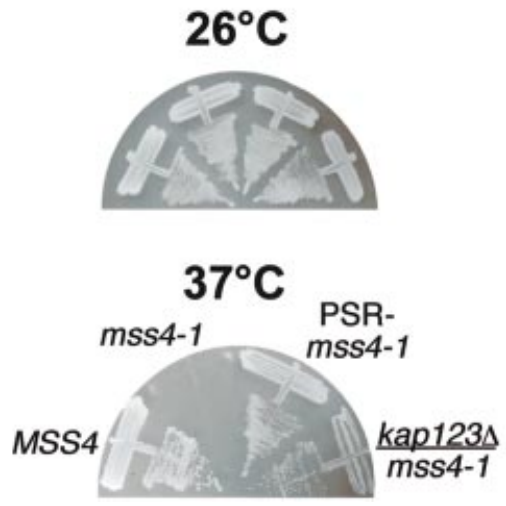

D

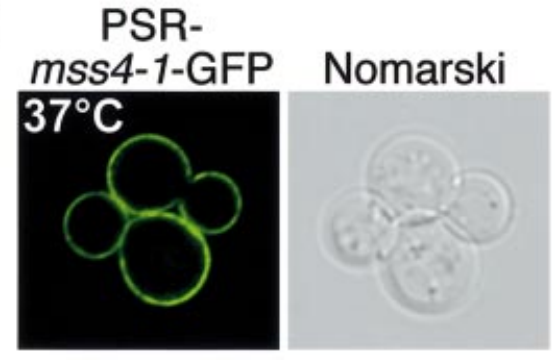

E

Mss4-GFP

mss4-1-GFP

PSR-mss4-1-GFP

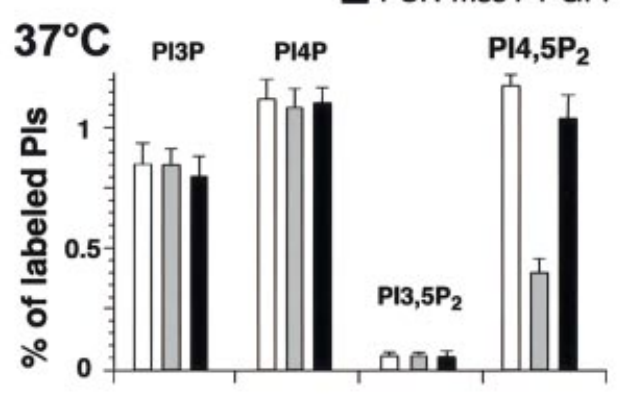

F Overexpressed mss 4 K360,362A DAPI
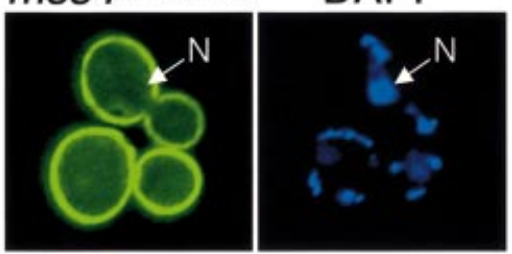

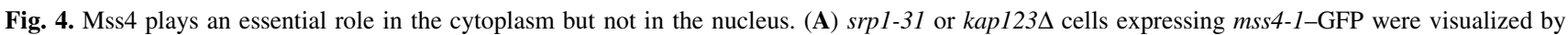

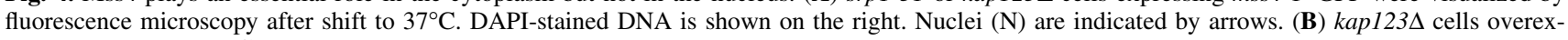
pressing Mss4-GFP. (C) $m s s 4 \Delta$ or $m s s 4 \Delta /$ kap $123 \Delta$ cells expressing MSS4-GFP, $m s s 4-1-G F P$ or PSR-mss4-1-GFP were grown at 26 or $37^{\circ} \mathrm{C}$ for 60 h. (D) $m s s 4 \Delta$ cells expressing PSR-mss4-1-GFP were visualized by fluorescence microscopy after shift to $37^{\circ} \mathrm{C}$. (E) Phosphoinositide levels in $m s s 4 \Delta$

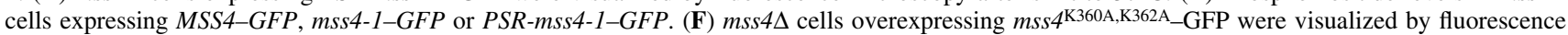
microscopy.

and mss4-6 (class II), both of which generated stable forms of Mss4 at all temperatures tested (data not shown).

We next analyzed phosphoinositide production in both classes of mutant cells. At the permissive temperature, each showed a relatively mild reduction in $\mathrm{PI} 4,5 \mathrm{P}_{2}$ synthesis as compared with cells expressing wild-type Mss4-GFP (Figure 3B). The most severe defect (2-fold) was observed in mss4-6 cells, which also exhibited a slightly reduced growth rate at the permissive temperature. Following a very brief shift to the elevated temperature (10 min), cells expressing wild type Mss4-GFP showed normal heat shock-induced $\mathrm{PI}_{4}, 5 \mathrm{P}_{2}$ synthesis, but in contrast, both classes of mss 4 mutant cells showed reduced levels of $\mathrm{PI} 4,5 \mathrm{P}_{2}$ synthesis (Figure $3 \mathrm{C}$ ). Again, the most severe defect was observed in mss4-6 cells, which generated $<10 \%$ of the PI4,5 $\mathrm{P}_{2}$ levels normally seen in wild-type cells. $m s s 4-1$ cells showed a 3 -fold reduction in $\mathrm{PI} 4,5 \mathrm{P}_{2}$ synthesis under similar conditions; however, an extended preincubation of mss4-1 cells at the nonpermissive temperature $(30 \mathrm{~min}$ ) caused a further reduction in $\mathrm{PI} 4,5 \mathrm{P}_{2}$ synthesis, similar to that observed in mss4-6 cells (data not shown). This defect in $\mathrm{PI} 4,5 \mathrm{P}_{2}$ synthesis was not a consequence of cell inviability or loss of cell wall integrity, since mss $4-1$ cells remain viable and intact for $>2 \mathrm{~h}$ at $37^{\circ} \mathrm{C}$.

Sequence analysis of the mutant alleles showed that mss4-6 (K197R, F484S, I498M, R673G, V736G) contained several mutations in the $\mathrm{C}$-terminal kinase domain 
of Mss4 (amino acids 463-755), while mss4-1 contained only two mutations, both in the N-terminal half of the protein (D127N, L393P). Together, these data suggest that the temperature-sensitive phenotype of mss $4-1$ is due to mislocalization as opposed to mss4-6, which exhibits a potent defect in kinase activity but remains associated with the plasma membrane. Moreover, the decrease in PI4,5 $\mathrm{P}_{2}$ production exhibited by mss $4-1$ cells suggests that nuclear localization of Mss4 limits its activity in vivo, suggesting a new mechanism for regulation of $\mathrm{PI} 4,5 \mathrm{P}_{2}$ synthesis through nuclear sequestration of the Mss4 kinase. Consistent with this idea, both mss4- 1 and mss4-6 cells exhibited a potent defect in actin cytoskeleton organization, similar to that observed in other temperatureconditional mss4 mutant cells.

\section{Plasma membrane anchoring of Mss4 rescues specific mss4 mutant cells}

Nuclear protein import is mediated by the action of soluble transport factors, including importins and karyopherins (Ryan and Wente, 2000). To determine if nuclear sequestration of Mss4 was directly responsible for the temperature sensitivity of $m s s 4-1$, we screened several nuclear importins known to be required for nuclear protein import. Surprisingly, the importin typically associated with recognition of classical bipartite NLSs, importin- $\alpha$ (Srp1), was dispensable for nuclear accumulation of Mss4 (Figure 4A). However, deletion of a specific importin- $\beta$ homolog KAP123 dramatically reduced nuclear import of mss4-1-GFP. The mutant form of Mss4 was not maintained at the plasma membrane, but instead accumulated in the cytoplasm (Figure 4A). Consistent with these findings, Mss4 failed to accumulate significantly in the nucleus when overexpressed in kap123A cells (Figure 4B). To determine whether KAP123 deletion was sufficient to rescue $m s s 4-1$ cells by preventing Mss 4 nuclear import, we examined growth of these double mutant cells at the nonpermissive temperature. Strikingly, deletion of KAP123 was found to rescue the temperature sensitivity of $m s s 4-1$ cells, although these double mutant cells grew slowly at elevated temperature (Figure 4C). Together, these data strongly suggest that Kap123 plays an important role in the regulation of Mss4 function.

We next investigated whether membrane tethering of Mss4 at the plasma membrane could rescue the temperature-sensitive growth defect of mss 4 mutant cells. To do this, we fused a peptide to the N-terminus of Mss4 encoding the first 28 amino acids of Psr1, a plasma membrane phosphatase required for sodium stress response, which has previously been shown to be dually palmitoylated and restricted from the nucleus (Siniossoglou et al., 2000). Examination of this palmitoylated form of $m s s 4-1-$ GFP (PSR-mss4-1-GFP) showed the fusion protein exclusively localized to the plasma membrane at elevated temperature, while mss4-1-GFP lacking this peptide was mostly found within the nucleus under identical conditions (Figure 4D). Moreover, fusion of the palmitoylated peptide to mss $4-1$ rescued both its temperature-sensitive growth defect and dramatically improved its defect in $\mathrm{PI} 4,5 \mathrm{P}_{2}$ synthesis (Figure $4 \mathrm{C}$ and $\mathrm{E}$ ). In contrast, this peptide failed to rescue the mss $4-6$ mutant protein that is not mislocalized. Together, these data show that $\mathrm{PI} 4,5 \mathrm{P}_{2}$ synthesis outside of the nucleus is essential for cell viability, while nuclear import of Mss4 likely serves a regulatory function that is dispensable under normal laboratory growth conditions. Consistent with this observation, cells expressing a mutant form of Mss4 lacking a functional NLS are viable and generate normal levels of $\mathrm{PI} 4,5 \mathrm{P}_{2}$, but fail to localize Mss4 to the nucleus even when overexpressed (Figure 4F).

\section{Mss4 is a substrate for casein kinase I on the plasma membrane}

Previous studies of different PI4P 5-kinases have suggested that this family of lipid kinases may also be regulated by phosphorylation (Park et al., 2001). To test whether Mss4 is a phosphoprotein, cells expressing Mss4GFP were labeled with ${ }^{32} \mathrm{P}$-labeled orthophosphate, immunoprecipitated with anti-GFP antibodies and subjected to SDS-PAGE analysis. After $10 \mathrm{~min}$ of labeling, a single weak band corresponding to Mss4-GFP was observed, but after 40 min of labeling, a stronger, slightly higher molecular weight band corresponding to Mss4GFP was clearly apparent (Figure 5A). This was not due to phosphorylation of GFP, as both HA- and Myc-tagged forms of Mss4 were also phosphorylated (data not shown). These data clearly demonstrate that Mss4 is a phosphoprotein.

The shift in molecular weight observed in the phosphorylation study could be the result of hyperphosphorylation. To determine if this was the case, cells were pulse labeled with ${ }^{35} \mathrm{~S}$-labeled cysteine and methionine, and immunoprecipitated using GFP antibody at different timepoints. Prior to SDS-PAGE analysis, samples were either treated with shrimp alkaline phosphatase to remove phosphate groups, or with buffer alone. In the absence of phosphatase, a change in the gel mobility of Mss4-GFP was observed between the two timepoints, but in the presence of phosphatase this shift was eliminated, indicating that the gel mobility shift was due to phosphorylation of Mss4 (Figure 5B).

To test whether the localization of Mss4 influenced its state of phosphorylation, mutant forms of Mss4 were examined. Interestingly, a defect in Mss4 phosphorylation specifically correlated to loss of plasma membrane association. Importantly, mss4-1-GFP, which localizes to the plasma membrane at permissive temperature, showed normal phosphorylation at this temperature, but was no longer phosphorylated at the restrictive temperature, where plasma membrane association was lost (Figure 5C). In contrast, mss4-6-GFP, which localizes to the plasma membrane independent of temperature, was normally phosphorylated under both conditions tested. These results were confirmed by ${ }^{32} \mathrm{P}$-labeling of cells expressing the different mutant forms of Mss4 (data not shown). Together, our data suggest that Mss4 is phosphorylated at the plasma membrane. Moreover, this is not simply due to autophosphorylation, as a kinase-defective form of Mss4 (mss4 $\left.4^{\mathrm{K} 496 \mathrm{~A}}\right)$ is normally phosphorylated (data not shown).

To identify the protein kinase(s) responsible for Mss4 phosphorylation, we systematically examined phosphorylation of Mss4 in mutant cells lacking specific protein kinase activities that are known to associate with the plasma membrane. Mss4 was normally phosphorylated in most mutant cells tested, including $p k c 1^{\text {ts }}, b c k 1 \Delta$, slt $2 \Delta$, 
A

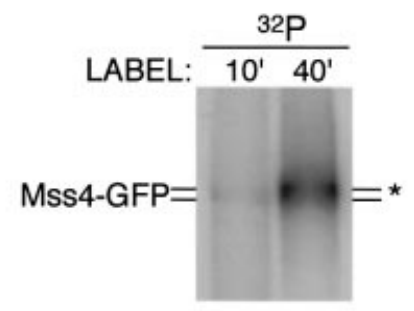

B
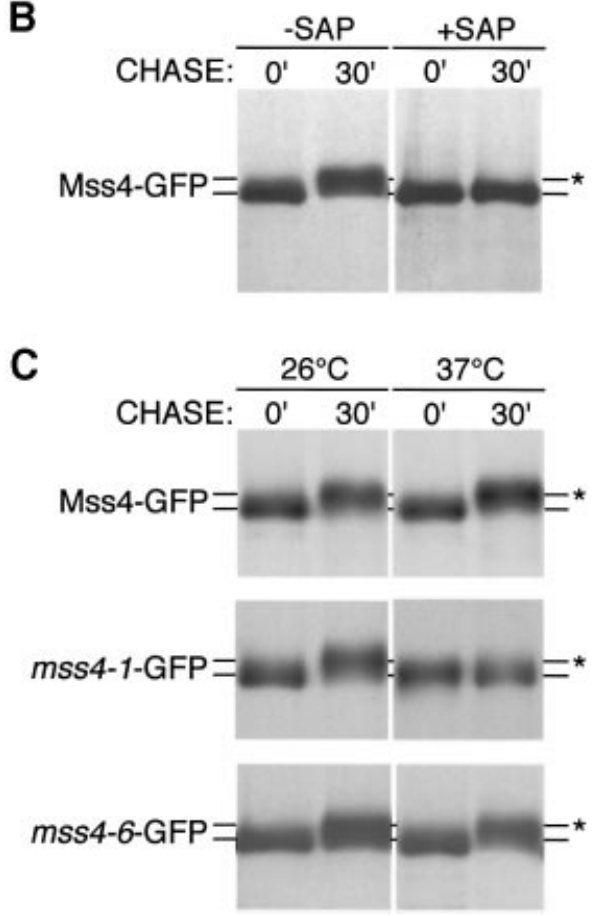

D

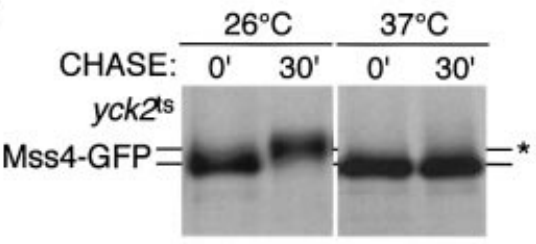

E

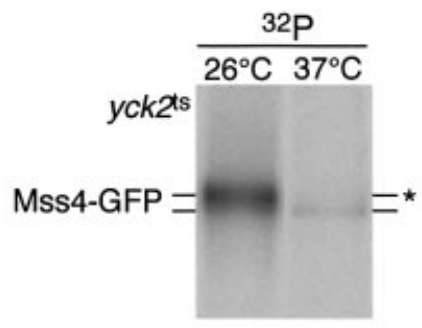

Fig. 5. Mss 4 is a substrate for casein kinase I at the plasma membrane. (A and E) $m s s 4 \Delta$ or $y c k 1 \Delta / y c k 2^{\text {ts }}$ cells expressing $M S S 4-G F P$ were metabolically labeled at the appropriate temperature for the indicated time with ${ }^{32} \mathrm{P}$-labeled orthophosphate. Extracts were immunoprecipitated with anti-GFP antibodies, followed by SDS-PAGE analysis and autoradiography. (B-D) $m s s 4 \Delta$ cells or $y c k 1 \Delta / y c k 2^{\text {ts }}$ expressing $M S S 4-G F P$, $m s s 4-1-G F P$ or mss4-6-GFP were metabolically labeled for $10 \mathrm{~min}$ with ${ }^{35} \mathrm{~S}$-labeled cysteine and methionine, and chased for the indicated time. Extracts were immunoprecipitated with anti-GFP antibodies, incubated in the presence or absence of shrimp alkaline phosphatase, and subjected to SDS-PAGE analysis followed by autoradiography. Asterisks indicate the mobility of hyperphosphorylated Mss4.

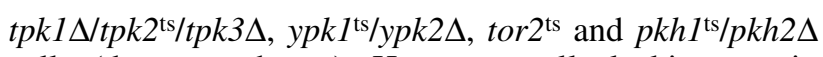
cells (data not shown). However, cells lacking casein kinase I activity, encoded by Yck1 and Yck2, showed a dramatic defect in Mss4 phosphorylation as assayed by gel mobility shift (Figure 5D). To confirm that casein kinase I was responsible for Mss4 phosphorylation, $y c k l \Delta / y c k 2^{\text {ts }}$ cells expressing Mss4-GFP were labeled at permissive and non-permissive temperatures with ${ }^{32} \mathrm{P}$-labeled orthophosphate, and immunoprecipitated for Mss4-GFP. At the permissive temperature, Mss4 was normally phosphorylated, but at the non-permissive temperature, Mss4 showed a dramatic reduction in phosphorylation (Figure 5E). In contrast, $c k a l \Delta / c k a 2^{\text {ts }}$ mutant cells, which lack casein kinase II activity at the non-permissive temperature, showed normal phosphorylation of Mss4-GFP, indicating that Mss 4 is specifically phosphorylated by casein kinase I.

To assay the direct effect of casein kinase I inactivation on Mss4 localization, $y c k 1 \Delta / y c k 2^{\text {ts }}$ cells radiolabeled at permissive and non-permissive temperatures with ${ }^{35} \mathrm{~S}$ labeled cysteine and methionine were fractionated into pelletable and soluble pools that were immunoprecipitated for Mss4. At the permissive temperature, a significant fraction of Mss4 was pelletable due to association with the plasma membrane, but in the absence of casein kinase I activity, newly synthesized Mss4 became mostly soluble, although a small fraction of unphosphorylated Mss 4 could still associate with the membrane fraction (Table I). Furthermore, when $y c k 1 \Delta / y c k 2^{\text {ts }}$ cells were radiolabeled at permissive temperature and then shifted to non-permissive temperature for $40 \mathrm{~min}$, phosphorylation of Mss4 was diminished, indicating that Mss4 is subject to a cycle of phosphorylation and dephosphorylation, consistent with a role for phosphorylation in the regulation of Mss4 activity/ localization (data not shown). However, Mss4 failed to significantly accumulate in the nucleus in $y c k l \Delta / y c k 2^{\text {ts }}$ cells (Table II). Nevertheless, these data argue that efficient/stable association of Mss4 with the plasma membrane is at least partially dependent on phosphorylation by casein kinase I, but likely also involves other protein-protein interactions.

\section{Allele-specific suppression of mss4 mutant cells}

To understand the role for nuclear sequestration in the regulation of Mss4 localization further, we isolated gene 
Table I. Subcellular distribution of newly synthesized Mss4

\begin{tabular}{llllll}
\hline Protein & \multicolumn{2}{l}{ Wild type } & & \multicolumn{2}{l}{$y c k 1 \Delta / y c k 2^{\text {ts }}$} \\
\cline { 2 - 3 } \cline { 6 - 6 } \cline { 5 - 6 } & Pellet & Supernatant & & Pellet & Supernatant \\
\hline Mss4-GFP & $65 \%$ & $35 \%$ & & $5 \%$ & $95 \%$ \\
G6PDH (soluble) & $<5 \%$ & $95 \%$ & & $<5 \%$ & $95 \%$ \\
Pep12 (membrane) & $95 \%$ & $<5 \%$ & & $95 \%$ & $<5 \%$ \\
\hline
\end{tabular}

Cells were grown to mid-log phase, converted to spheroplasts, shifted to $38^{\circ} \mathrm{C}$ for $10 \mathrm{~min}$, labeled for $20 \mathrm{~min}$ with Tran ${ }^{35} \mathrm{~S}$ label, chased for $40 \mathrm{~min}$ with an excess of unlabeled cysteine and methionine, and osmotically lysed. Extracts were separated by differential centrifugation, and Mss4-GFP was detected by immunoprecipitation. Percentage of total Mss4-GFP as determined by densitometry is shown for both fractions.

dosage-dependent suppressors of mss $4-1$ mutant cells at the non-permissive temperature $\left(37^{\circ} \mathrm{C}\right)$. Multiple colonies were isolated based on robust growth, and plasmid recovery followed by sequence analysis revealed that either the $M S S 4$ or the $B C P 1$ genes were responsible for the rescue of mss4-1 temperature sensitivity. $B C P 1$ is an uncharacterized, essential gene, which possesses significant homology to a mammalian protein encoded by BCCIP (also known as Tok-1), a BRCA2 and p21/CIP interacting protein (Ono et al., 2000; Liu et al., 2001).

To determine if Mss4 localization was affected by $B C P 1$ expression, cells expressing mss4-1-GFP were transformed with both an endoplasmic reticulum/nuclear envelope marker encoded by HDEL-DsRed (Bevis et al., 2002), and either vector alone or a plasmid overexpressing $B C P 1$. At the non-permissive temperature, mss4-1-GFP accumulated in the nucleus in cells containing vector alone, but in cells that overexpressed Bcp1 (5- to 10-fold), Mss4 no longer accumulated in the nucleus; rather, plasma membrane localization of Mss4 was restored (Figure 6A). Consistent with the restoration of Mss4 localization to the plasma membrane, the defect in actin cytoskeleton organization observed in mss4-1 cells was alleviated (Figure 6B). Additionally, overexpression of BCP1 increased levels of $\mathrm{PI} 4,5 \mathrm{P}_{2}$ production in mss $4-1$ cells $\sim 2$-fold at the non-permissive temperature (Figure $6 \mathrm{C}$ ). However, overexpression of $B C P 1$ failed to rescue mss 4-6 mutant cells that do not accumulate Mss4 within the nucleus, suggesting that Bcp1 regulates Mss4 localization and rescues mutants that accumulate Mss4 in the nucleus by increasing Mss4 nuclear export.

\section{Bcp1 regulates Mss4 activity/localization}

To further investigate the role of Bcp1 in Mss4 function and localization, we first generated a temperature-sensitive form of the protein using PCR mutagenesis, followed by plasmid shuffle techniques. Interestingly, alleles of mss 4 were lethal in combination with the temperature-sensitive bcpl allele. To determine if $b c p 1^{\text {ts }}$ mutant cells exhibit a defect in $\mathrm{PI} 4,5 \mathrm{P}_{2}$ production, phosphoinositide lipids were analyzed in $b c p l^{\text {ts }}$ cells. At the permissive temperature, there was no effect on phosphoinositide production in $b c p 1^{\text {ts }}$ cells compared to an isogenic strain carrying a wildtype copy of $B C P 1$. However, at the elevated temperature, $b c p 1^{\text {ts }}$ cells exhibited a complete absence of heat shockinduced $\mathrm{PI} 4,5 \mathrm{P}_{2}$ synthesis (Figure 7A). In addition,

\begin{tabular}{lcc}
\hline \multicolumn{2}{l}{ Table II. Subcellular localization of Mss4-GFP } \\
\hline Strain & $26^{\circ} \mathrm{C}$ & $37^{\circ} \mathrm{C}$ \\
\hline Wild type & $\mathrm{PM}$ & $\mathrm{PM}$ \\
$m s s 4-1$ & $\mathrm{PM}$ & $\mathrm{N}$ \\
$c r m 1^{\mathrm{T} 539 \mathrm{C}}$ & $\mathrm{PM}$ & $\mathrm{ND}$ \\
$x p o 1-1$ & $\mathrm{PM}$ & $\mathrm{PM}$ \\
$c s e 1-2$ & $\mathrm{PM}$ & $\mathrm{PM}$ \\
$l o s 1 \Delta$ & $\mathrm{PM}$ & $\mathrm{PM}$ \\
$m s n 5 \Delta$ & $\mathrm{PM}$ & $\mathrm{PM}$ \\
sac $3 \Delta$ & $\mathrm{PM}$ & $\mathrm{PM}$ \\
$b c p 1^{\text {ts }}$ & $\mathrm{PM}$ & $\mathrm{PM}$ \\
$y c k 1 \Delta / y c k 2-2$ & $\mathrm{PM}$ & $\mathrm{PM}$ \\
$b c p 1^{\mathrm{t}} / y c k 1 \Delta / y c k 2-2$ & $\mathrm{PM}$ & $\mathrm{N}^{\mathrm{c}}$ \\
\hline
\end{tabular}

$\mathrm{N}$, nuclear; PM, plasma membrane; ND, not determined. Cells expressing Mss4-GFP were grown at $26^{\circ} \mathrm{C}$, shifted to the indicated temperature for $2 \mathrm{~h}$ (unless otherwise specified) and visualized by fluorescence microscopy. Observations were based on visualization of $>50$ cells/condition.

${ }^{a}$ Cells were treated with leptomycin for $30 \mathrm{~min}$.

bWeak, but reproducible nuclear accumulation of Mss4-GFP was also observed in $>60 \%$ of cells.

${ }^{\mathrm{c} M s s} 4$ was also observed at the PM.

phosphorylation of newly synthesized Mss4 was defective in $b c p l^{\text {ts }}$ cells as assayed by gel mobility shift (Figure 7B). Interestingly, extended incubations at the non-permissive temperature resulted in reduced amounts of Mss4 phosphorylation (Figure 7C). Since Mss4 phosphorylation correlates with plasma membrane targeting of Mss4, these results suggest that $b c p 1^{\text {ts }}$ cells fail to accumulate Mss4 properly at the plasma membrane. Consistent with this idea, fusion of the Psr1 sorting signal to Mss4, which targets Mss4 to the plasma membrane, bypassed the requirement for Bcp1 in Mss4 phosphorylation (Figure 7D).

Surprisingly, only a small fraction of Mss4-GFP was reproducibly observed in the nucleus in $b c p I^{\text {ts }}$ cells at the non-permissive temperature (Table II), again suggesting that the rate of Mss4 nuclear import is slow and/or tightly regulated. In contrast, multiple other previously characterized factors implicated in nuclear protein export, including Cse1, Crm1/Xpo1, Los1, Msn5 and Sac3, were dispensable for Mss4 nuclear export (Table II). Since phosphorylation of Mss4 was found to be important for its stable membrane association, we examined Mss4 localization in $b c p l^{\text {ts }}$ cells also lacking casein kinase I activity. In contrast to $b c p 1^{\text {ts }}$ and $y c k 1 \Delta / y c k 2^{\text {ts }}$ cells, $b c p 1^{\text {ts }} / y c k 1 \Delta / y c k 2^{\text {ts }}$ triple mutant cells exhibited a significant synthetic growth defect at $26^{\circ} \mathrm{C}$, indicating a genetic interaction between $\mathrm{Bcp} 1$ and casein kinase I. Following shift to the non-permissive temperature, $b c p 1^{\text {ts }} / y c k 1 \Delta / y c k 2^{\text {ts }}$ mutant cells accumulated Mss4 within the nucleus, although a pool of Mss4 did remain associated with the plasma membrane (Figure 8A), suggesting that additional factors are involved in Mss4 localization to the plasma membrane. These data suggest that together with casein kinase I activity at the plasma membrane, Bcp1 is required for preventing nuclear accumulation of Mss4.

To demonstrate more convincingly that Bcp1 functions in nuclear protein export, we analyzed localization of a well characterized complex that is exported from the nucleus, the large $60 \mathrm{~S}$ ribosomal subunit, in $b c p 1^{\text {ts }}$ cells. 

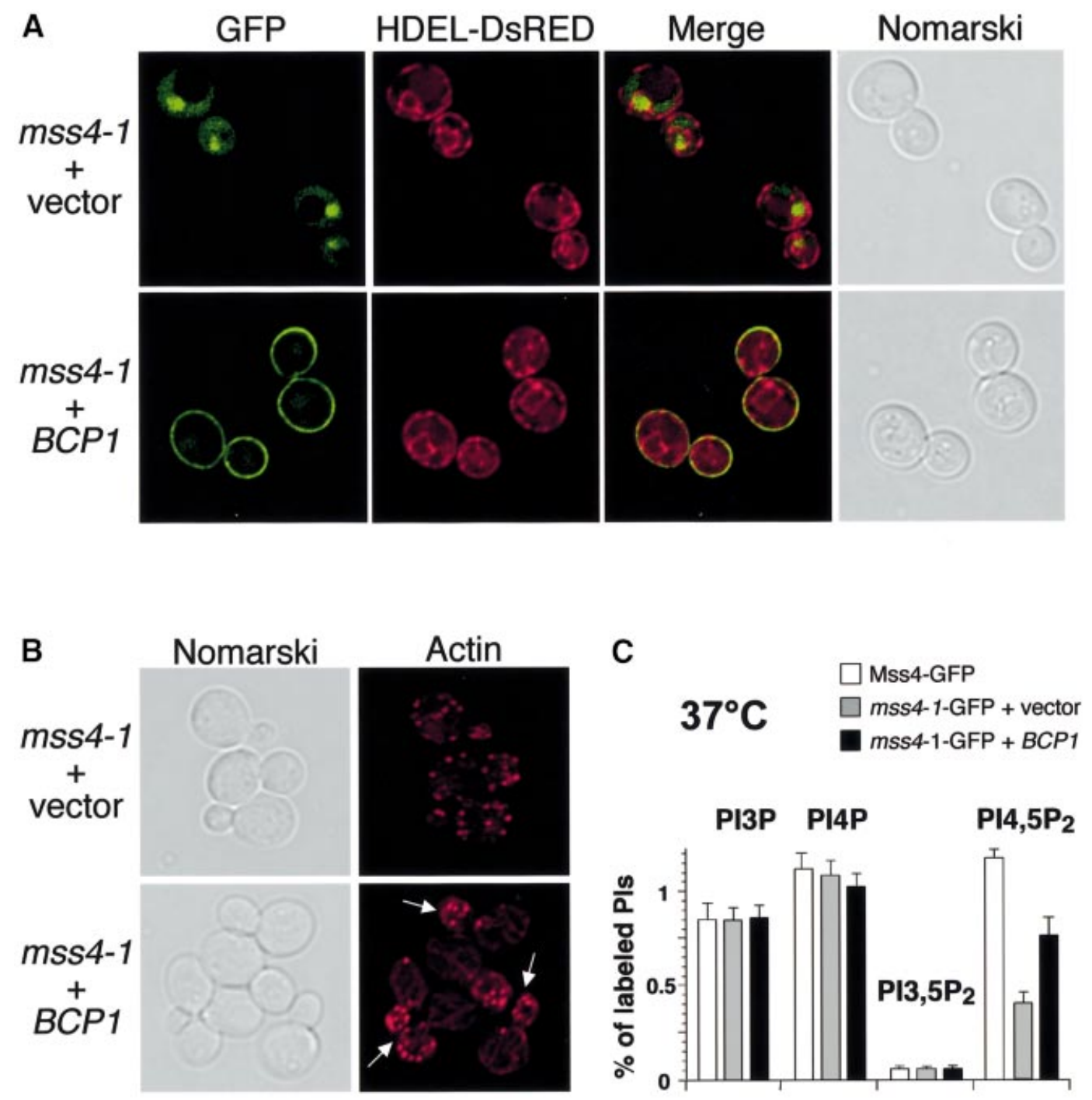

Fig. 6. Bcp1 regulates Mss4 nuclear export. (A) $m s s 4 \Delta$ cells expressing $m s s 4-1-G F P$ or $H D E L-D s R e d$, and those overexpressing either empty vector or a plasmid carrying $B C P 1$, were visualized by fluorescence microscopy. (B) $m s s 4 \Delta$ cells expressing $m s s 4-1-G F P$ and overexpressing either empty vector or a plasmid carrying $B C P 1$ were stained with rhodamine-phalloidin and visualized by fluorescence microscopy. Arrows indicate buds with polarized actin localization. (C) Phosphoinositide levels in $m s s 4 \Delta$ cells expressing MSS4-GFP or $m s s 4-1-G F P$, and overexpressing vector alone or a plasmid carrying $B C P 1$.

Previous studies using Rpl11b-GFP have shown that a temperature-sensitive yeast strain impaired in $60 \mathrm{~S}$ ribosomal subunit assembly or transport should accumulate Rpl11b in the nucleus following return to a permissive temperature if the rate of ribosome synthesis is faster than the rate at which the mutant phenotype reverses (StageZimmermann et al., 2000). At the permissive temperature, Rpl11b-GFP was mostly excluded from the nucleus in $b c p t^{\text {ts }}$ cells, but after a $1 \mathrm{~h}$ shift to non-permissive temperature and return to permissive temperature (30 $\min$ ), Rpl11b-GFP was enriched in the nucleus, suggesting a defect in ribosomal subunit export (Figure 8B). In contrast, wild-type cells failed to accumulate Rpl11b-GFP in the nucleus. These data, together with our previous findings, strongly suggest that Bcp1 is essential for nuclear export of both Mss 4 and the 60S ribosomal subunit.

Previous studies have shown that mutations in multiple nuclear export factors, including Cse1, result in defects in cell cycle progression (Xiao et al., 1993). To determine whether $b c p 1^{\text {ts }}$ cells show a similar defect, $b c p t^{\text {ts }}$ cells were incubated at the non-permissive temperature for $2 \mathrm{~h}$, fixed and stained with DAPI. In general, most $b c p 1^{\text {ts }}$ cells (>80\%) appeared to arrest with large buds that failed to undergo nuclear division (Figure 8C). This cell cycle arrest was independent of the mitotic checkpoint, as deletion of $M A D 2$ or $B U B 2$ failed to permit cell cycle progression at the non-permissive temperature. Interestingly, nuclei appear at the mother-bud neck in arrested $b c p 1^{\text {ts }}$ cells. Consistent with this defect in nuclear division/segregation, $b c p 1^{\text {ts }}$ cells exhibited a defect in mitotic spindle elongation (Figure 8D). Most large budded cells exhibited a short mitotic spindle that failed to extend into daughter cells. In contrast, wild-type cells with similar sized buds showed segregated spindle poles or elongated mitotic spindles characteristic of cells at this stage of the cell cycle. These data suggest that Bcp1 may be essential for normal shuttling of nuclear proteins needed for the $\mathrm{G}_{2} /$ $M$ transition, similar to other essential nuclear protein 
A
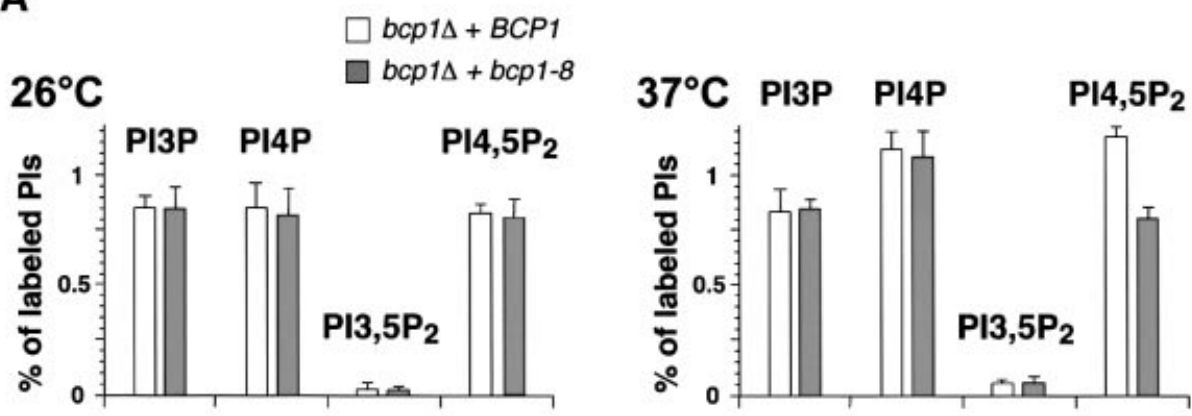

B

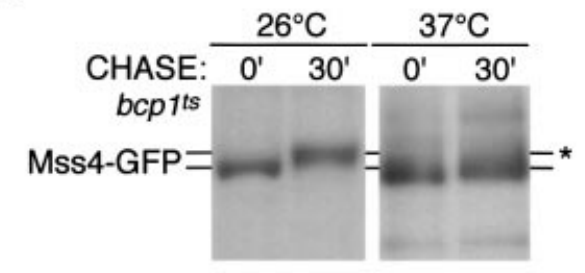

D

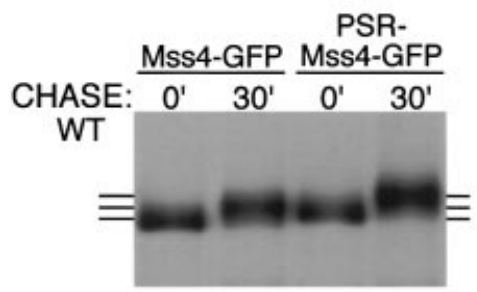

C

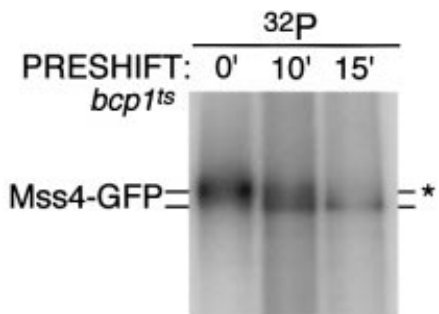

PSRMss4-GFP Mss4-GFP

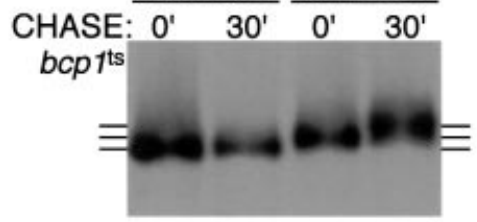

Fig. 7. Bcp1 is required for appropriate function and localization of Mss4. (A) Phosphoinositide levels in $b c p 1 \triangle$ cells expressing wild-type $B C P 1$ or $b c p 1^{\text {ts }}$. (B) $b c p 1^{\text {ts }}$ cells expressing MSS4-GFP were treated as described in Figure 5C. (C) $b c p 1^{\text {ts }}$ cells expressing MSS4-GFP were preincubated at $37^{\circ} \mathrm{C}$ for the indicated time and metabolically labeled with ${ }^{32} \mathrm{P}$-labeled orthophosphate. Extracts were treated as described in Figure 5A. Asterisks indicate the mobility of hyperphosphorylated Mss4. (D) Wild-type or bcp $1^{\text {ts }}$ cells expressing MSS4-GFP or PSR-MSS4-GFP were metabolically labeled at $37^{\circ} \mathrm{C}$ for $10 \mathrm{~min}$ with ${ }^{35} \mathrm{~S}$-labeled cysteine and methionine, and chased for the indicated time. Extracts were treated as above.

export factors. Consistent with this idea, generation of a functional GFP fusion to Bcp1 showed it to be enriched in the nucleus, similar to the localization of its mammalian homolog BCCIP and other proteins known to be important for nuclear protein export (Figure 8E). Additionally, deletion of KAP123, important for nuclear import of both Mss4 and 60S ribosomal subunits, partially suppressed the temperature sensitivity of $b c p I^{\text {ts }}$ cells, albeit weakly, suggesting that defects in nuclear protein import may help prevent accumulation of specific proteins in the nucleus in $b c p t^{\text {ts }}$ cells. Taken together, these studies strongly suggest that Mss4 cycles between the nucleus and cytoplasm, which is at least in part dependent on Kap123 and $\mathrm{Bcp} 1$, thereby regulating $\mathrm{PI} 4,5 \mathrm{P}_{2}$ synthesis at the plasma membrane.

\section{Discussion}

We have demonstrated previously an important role for the Mss4 PI4P 5-kinase at the plasma membrane in activation of the Rho1 GTPase, which is essential for actin cytoskeleton organization (Audhya and Emr, 2002). Moreover, tight regulation of PI4,5 $\mathrm{P}_{2}$ levels by phosphoinositide phosphatases at the plasma membrane was required for appropriate activation of the Rho1/Pkc1mediated MAP kinase cascade. We now report an additional key regulatory mechanism for $\mathrm{PI} 4,5 \mathrm{P}_{2}$ synthesis at the plasma membrane, through the nuclear-cytoplasmic shuttling of the Mss4 PI4P 5-kinase. First, we identified a functional bipartite NLS in Mss4. Secondly, we isolated mutants that inappropriately retain Mss4 in the nucleus and show defects in Mss4 phosphorylation and cellular $\mathrm{PI} 4,5 \mathrm{P}_{2}$ synthesis, which is required for normal actin cytoskeleton organization. Thirdly, we showed that anchored localization of Mss4 to the plasma membrane or deletion of a soluble transport factor required for Mss4 nuclear import could rescue cells expressing mutant forms of Mss4 that are otherwise mislocalized in the nucleus. Finally, we identified an essential protein required for Mss4 nuclear exit that also regulates $\mathrm{PI} 4,5 \mathrm{P}_{2}$ production. Together, these studies show that Mss4 can shuttle between the cytoplasm and the nucleus, thereby regulating $\mathrm{PI} 4,5 \mathrm{P}_{2}$ synthesis at the plasma membrane. We suggest that this type of temporal and spatial regulation of lipid kinase signaling is important for compartmentalization of specific downstream events, including the $\mathrm{PI} 4,5 \mathrm{P}_{2^{-}}$ dependent activation of the Rho1/Pkc1 pathway at the plasma membrane (Figure 9). 
A
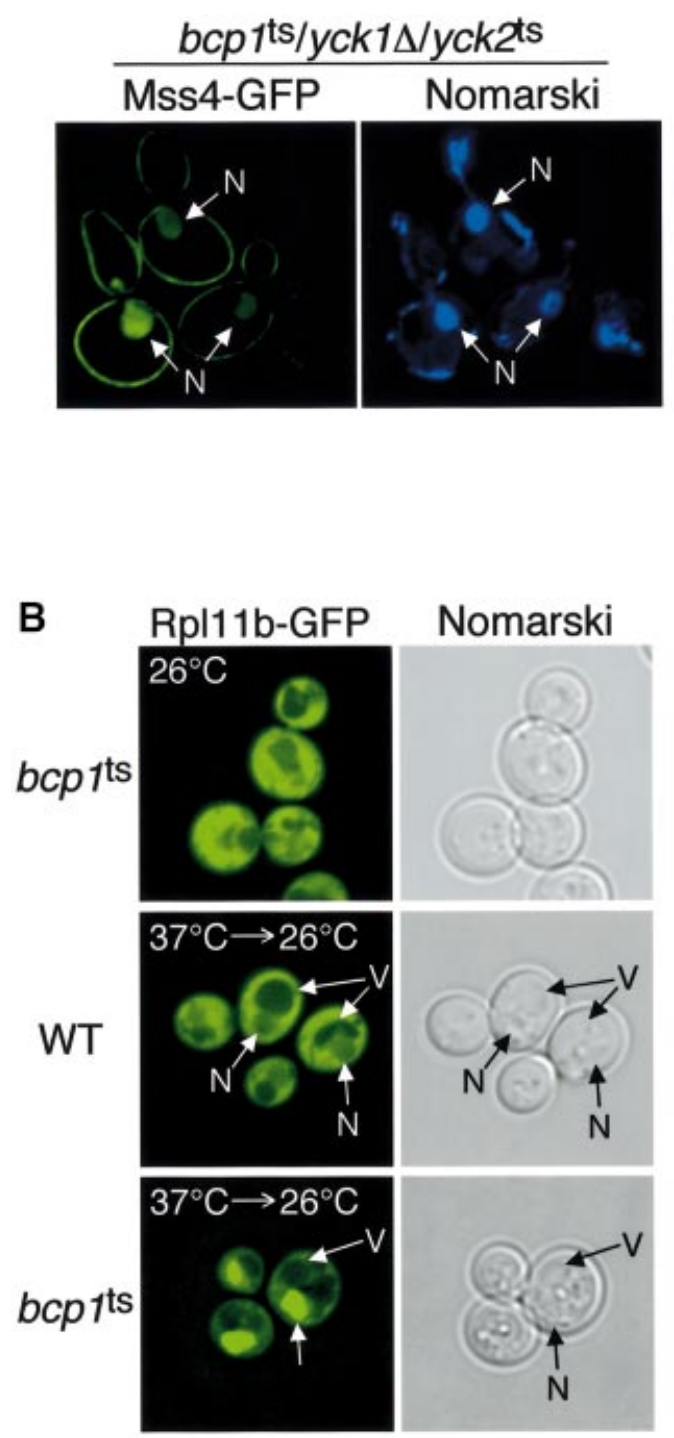
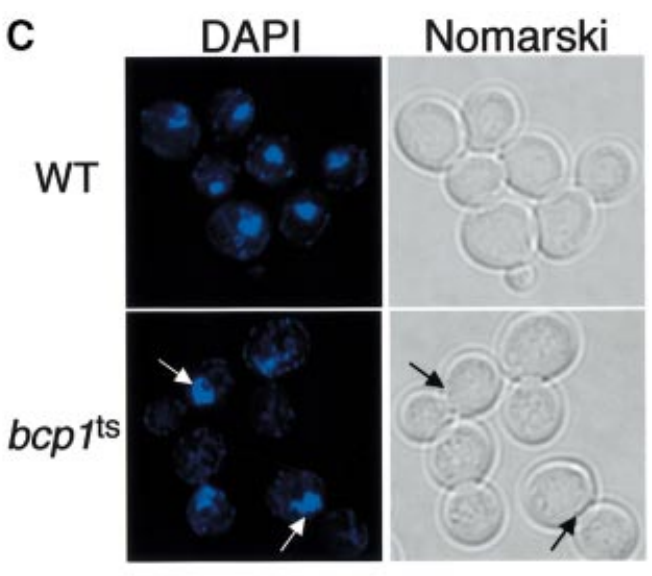

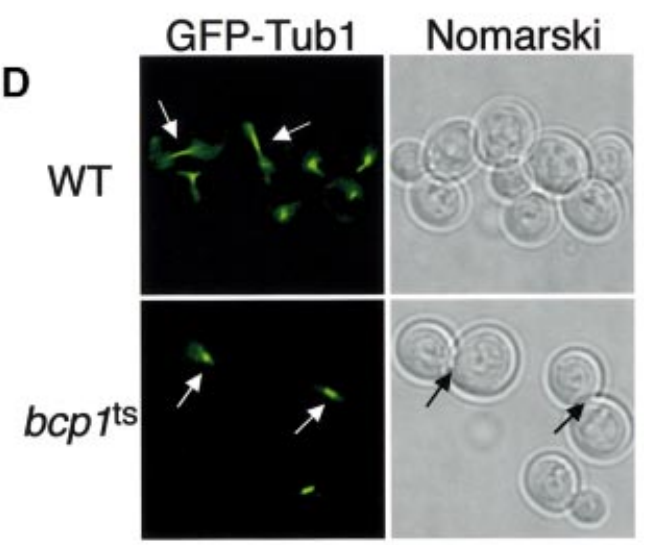

E

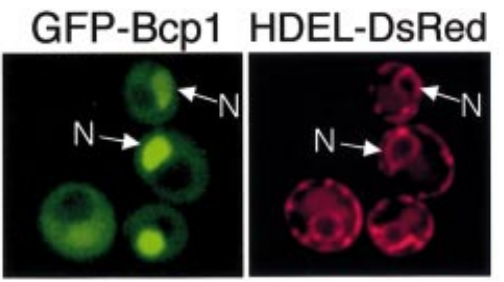

Fig. 8. Bcp1 is involved in nuclear protein export. (A) $b c p 1^{\text {ts }} / y c k 1 \Delta / y c k 2^{\text {ts }}$ cells expressing Mss4-GFP were visualized using fluorescence microscopy at the indicated temperature. DAPI-stained DNA is shown on the right. Nuclei $(\mathrm{N})$ are indicated by arrows. (B) Wild-type or $b c p 1^{\text {ts }}$ cells expressing RPL11B-GFP were visualized using fluorescence microscopy at the indicated temperature. Nuclei $(\mathrm{N})$ and vacuoles $(\mathrm{V})$ are indicated by arrows. (C) Wild-type or $b c p 1^{\text {ts }}$ cells were incubated at $37^{\circ} \mathrm{C}$ for $2 \mathrm{~h}$, fixed and stained with DAPI, and visualized by fluorescence microscopy. Arrows highlight the location of DAPI-stained nuclei. (D) Wild-type or $b c p I^{\text {ts }}$ cells expressing $G F P-T U B 1$ were incubated at $37^{\circ} \mathrm{C}$ for $2 \mathrm{~h}$ and visualized by fluorescence microscopy. Arrows highlight the mitotic spindle. (E) $b c p 1 \Delta$ cells expressing $G F P-B C P 1$ and HDEL-DsRED were visualized by fluorescence microscopy.

\section{A role for nuclear-cytoplasmic shuttling in phosphoinositide regulation}

Previous studies have indicated a role for nuclear shuttling in the regulation of multiple proteins. In some cases, external cues direct nuclear accumulation of proteins, such as the Hog1 MAP kinase in yeast, which is targeted to the nucleus by increased extracellular osmolarity, required for normal transcriptional activation of multiple genes (Ferrigno et al., 1998). In other cases, external cues cause the nuclear export of proteins, such as the yeast transcription factor Pho4, in response to extracellular phosphate content, thereby terminating expression of phosphate-responsive genes (O'Neill et al., 1996). We found that defects in nuclear export of a PI lipid kinase inhibited its normal function, suggesting that nuclear import of Mss4 may be a mechanism for regulating phosphoinositide synthesis at the plasma membrane. Interestingly, phosphorylation of multiple proteins, including the transcriptional regulator Pho4, is important for their appropriate subcellular localization (Kaffman et al., 1998). In the case of Pho4, phosphorylation has been suggested to unmask a nuclear export signal, which can be recognized by the Msn5 nuclear protein export factor (Kaffman et al., 1998). We found that Mss4 phosphorylation is important for maintaining its association with membranes, and mutant forms of Mss4 that accumulate in the nucleus fail to be phosphorylated normally. Further studies will be required to determine if phosphorylation of Mss4 masks its NLS, thereby preventing association with its major transport factor Kap123, and/or unmasks a 


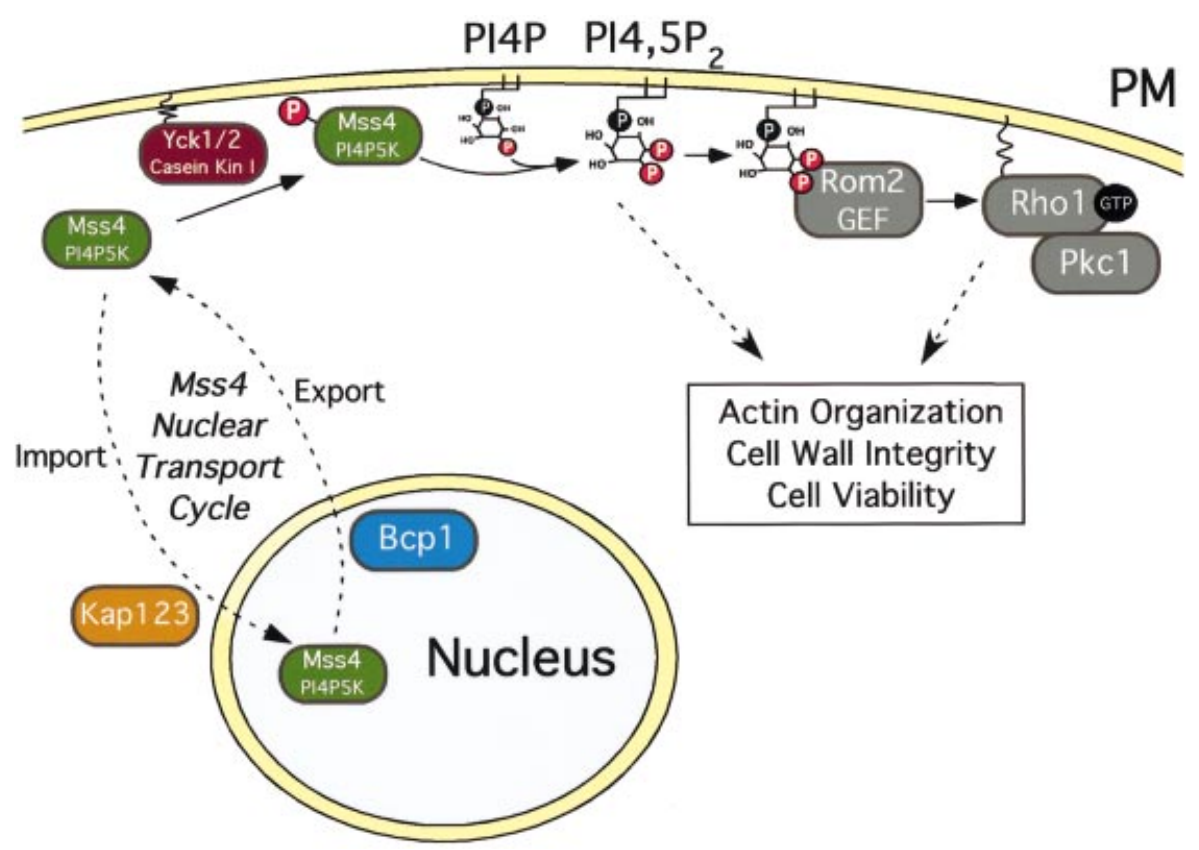

Fig. 9. Model for the regulation of Mss4 localization/activity involving phosphorylation by Yck1/2, nuclear import by Kap123 and nuclear export by Bcp1. The plasma membrane is denoted by PM.

binding site for a plasma membrane receptor. However, we have shown that defects in phosphorylation of Mss4 by casein kinase I do result in a partial reduction in Mss4 association with the pelletable membrane fraction, consistent with a role for phosphorylation in promoting plasma membrane association and thereby preventing nuclear import. Consistent with this idea, casein kinase I became essential for maintenance of Mss4 at the plasma membrane in the absence of normal Bcp1 function. These data suggest that multiple signals, both at the plasma membrane and the nucleus, contribute to localization of Mss4. However, even in $b c p 1^{\text {ts }} / y c k 1 \Delta / y c k 2^{\text {ts }}$ triple mutant cells, a pool of Mss4 remained associated with the plasma membrane, indicating that additional as yet unidentified factors participate in the targeting of Mss4.

\section{Potential roles for Bcp1 in the nucleus}

Our studies have also uncovered a role for the essential protein Bcp1 in nuclear protein export. Previously, Bcp1 was shown to exist in a complex with ribosomal subunits Rpl23a and Rpl23b (Ho et al., 2002), which is consistent with our finding that Bcp1 functions in the export of the $60 \mathrm{~S}$ ribosomal subunit. Additionally, a putative homolog of Bcp1 has been identified in mammalian cells, a BRCA2 interacting protein called BCCIP (Liu et al., 2001). Overexpression of $B C C I P$ can inhibit the growth of certain tumors, and recently a kidney tumor cell line was found to express reduced levels of BCCIP, suggesting a role for this protein in cancer, potentially through the regulation of BRCA2 function (Meng et al., 2003). Interestingly, if Bcp1 and BCCIP function similarly, our studies would suggest that appropriate nuclear exit may also be important for the function of BRCA2, similar to the previously described importance of nuclear export of p53 (Stommel et al., 1999). However, further studies are required to demonstrate directly the function of BCCIP and to determine whether nuclear export of BRCA2 is necessary for its function in vivo.

In addition to its interaction with BRCA2, BCCIP was also identified as a p21/CIP binding partner (Ono et al., 2000). p21/CIP is an inhibitor of cell cycle progression, acting on multiple cyclin-dependent kinases including Cdk2 (Harper et al., 1995). Again, nuclear-cytoplasmic shuttling of p21/CIP may play an important role in normal cell cycle regulation. Interestingly, $b c p 1^{\text {ts }}$ cells exhibited a defect in cell cycle progression, perhaps due to accumulation of proteins in the nucleus that are normally exported during $\mathrm{G}_{2} / \mathrm{M}$. Although yeast do not possess a p21/CIP homolog, a mechanism of cell cycle control involving Bcp1-dependent nuclear shuttling of cell cycle regulatory proteins may exist.

\section{Essential role for the PI4P 5-kinase Mss4 exists at the plasma membrane}

A homolog of Mss4 in mammalian cells, the Type I PI4P $5-\mathrm{K} \alpha$, has also been observed in the nucleus, where it is postulated to function in mRNA splicing (Boronenkov et al., 1998). Our studies suggest that PI4,5 $\mathrm{P}_{2}$ generation in the nucleus is not essential in yeast, as tethering of Mss4 to the plasma membrane or mutating the Mss4 NLS did not cause a defect in Mss4 function in vivo. However, a nonessential role for $\mathrm{PI} 4,5 \mathrm{P}_{2}$ in the nucleus cannot be ruled out, and further studies will be required to determine if $\mathrm{PI} 4,5 \mathrm{P}_{2}$ binding proteins exist in the nucleus or if a distinct pool of $\mathrm{PI} 4,5 \mathrm{P}_{2}$ generated in the nucleus is required for nuclear function. Interestingly, the PI4-kinase Pik1 has also been observed in the nucleus (Garcia-Bustos et al., 1994), and can cycle between the cytoplasm and nucleus similar to Mss4 (T.Strahl and J.Thorner, personal communication). However, a function for Pik1 in the nucleus has yet to be elucidated. 
Table III. Saccharomyces cerevisiae strains used in this study

\begin{tabular}{|c|c|c|}
\hline Strain & Genotype & Reference or source \\
\hline SEY6210 & Mato leu2-3,112 ura3-52 his3- $\Delta 200$ trp1- $\Delta 901$ lys2-801 suc2- $\Delta 9$ & Robinson et al. (1988) \\
\hline SEY6210.1 & Mata leu2-3,112 ura3-52 his3- $\Delta 200$ trp1- $\Delta 901$ lys2-801 suc2- $\Delta 9$ & Robinson et al. (1988) \\
\hline RH4336 & leu2 ura3 trp1 yck1 $1 \Delta$ ck2-2 & Friant et al. (2000) \\
\hline AAY1207 & SEY6210; MSS4-GFP:HIS3MX6 & This study \\
\hline AAY1220 & SEY6210; mss4A::HIS3MX6 carrying pRS415 MSS4-GFP (LEU2 CEN6 MSS4-GFP) & This study \\
\hline AAY1221 & SEY6210; mss4 $\because: H I S 3 M X 6$ carrying pRS415 mss4-1-GFP & This study \\
\hline AAY1226 & SEY6210; mss $4 \Delta:: H I S 3 M X 6$ carrying pRS415 mss4-6-GFP & This study \\
\hline AAY1250 & SEY6210; mss4A::HIS3MX6 carrying pRS415 PSR-MSS4-GFP & This study \\
\hline AAY1251 & SEY6210; mss $4 \Delta:: H I S 3 M X 6$ carrying pRS415 PSR-mss4-1-GFP & This study \\
\hline AAY1256 & SEY6210; $m s s 4 \Delta:: H I S 3 M X 6$ carrying pRS415 PSR-mss4-6-GFP & This study \\
\hline AAY1262 & SEY6210; mss $4 \Delta:: H I S 3 M X 6$ carrying pRS414 mss4 ${ }^{\mathrm{K} 360 \mathrm{~A}, \mathrm{~K} 362 \mathrm{~A}}$ & This study \\
\hline AAY1312 & SEY6210; crm1 $::: L E U 2$ carrying pRS314 $\mathrm{crm}^{\mathrm{T} 539 \mathrm{C}}$ & This study \\
\hline AAY1337 & SEY6210; bcp1 $\triangle:: H I S 3$ carrying pRS414 BCP1 (TRP1 CEN6 BCP1) & This study \\
\hline AAY1341 & SEY $6210 ;$ bcp $1 \Delta:: H I S 3$ carrying pRS414 $b c p 1^{\text {ts }}$ & This study \\
\hline AAY1344 & AAY $1341 ; \operatorname{mad} 2 \Delta:: H I S 3$ & This study \\
\hline AAY1345 & AAY1341; bub2A::HIS3 & This study \\
\hline AAY1348 & SEY6210; bcp1 $1 \Delta:: H I S 3$ carrying pRS416 GFP-BCP1 (URA3 CEN6 GFP-BCP1) & This study \\
\hline AAY1478 & SEY6210; kap123A::HIS3 & This study \\
\hline AAY1482 & AAY1221; kap1234::HIS3 & This study \\
\hline AAY1492 & AAY1341; kap123A::HIS3 & This study \\
\hline AAY 1498 & RH4336; bcp1 $\Delta:: H I S 3$ carrying pRS414 bcp $1^{\text {ts }}$ & This study \\
\hline AAY1502 & SEY6210; srp1 $1:: H I S 3$ carrying pRS314 srp1-31 & This study \\
\hline AAY1504 & AAY1502; mss $4 \Delta:: H I S 3 M X 6$ carrying pRS415 $m s s 4-1-G F P$ & This study \\
\hline AAY1511 & SEY6210; cse1s::HIS3 carrying pRS314 cse1-2 & This study \\
\hline AAY1514 & SEY $6210 ;$ crm $1 \Delta:: L E U 2$ carrying pRS313 xpo1-1 & This study \\
\hline AAY1517 & SEY6210; los $1 \Delta:: H I S 3$ & This study \\
\hline AAY 1520 & SEY6210; $m s n 5 \Delta:: H I S 3$ & This study \\
\hline AAY1523 & SEY6210; sac3 $3:: H I S 3$ & This study \\
\hline
\end{tabular}

Finally, we have shown that a soluble transport factor Kap123 also plays a role in recognizing Mss4 for nuclear import. Interestingly, Kap123 and Bcp1 are both required for nuclear-cytoplasmic shuttling of the $60 \mathrm{~S}$ ribosomal subunit, suggesting that together, these proteins may regulate the localization of a number of other proteins in addition to Mss4. Also, deletion of KAP123 could weakly suppress the temperature sensitivity of $b c p l$ mutant cells, and Bcp1 and Kap123 have been shown to co-purify in a complex with the ribosomal subunit Rpl23A, further suggesting a connection between these proteins (Ho et al., 2002). Deletion of KAP123 did not completely abrogate nuclear accumulation of Mss4, perhaps due to the activity of the closely related importin Kap121/Pse1 (Rout et al., 1997). Previous studies have shown that Kap121 is important for nuclear import of Pho4, specifically in an unphosphorylated state (Kaffman et al., 1998). Similarly, Kap123 may only recognize unphosphorylated Mss4 as a substrate for nuclear import. In contrast to the role of Kap123 in nuclear import of Mss4, overexpression of Bcp1 both prevented nuclear accumulation of Mss4 and maintained Mss4 on the plasma membrane. This would suggest that Bcp1 may also play a role in directing Mss4 to the plasma membrane. How Bcp1 functions outside the nucleus will require further investigation. In addition, the regulatory mechanism by which Kap123 recognizes Mss4 for nuclear import will be important in further understanding of $\mathrm{PI} 4,5 \mathrm{P}_{2}$ regulation at the plasma membrane.

Together, our data indicate the existence of a previously unknown mechanism for $\mathrm{PI} 4,5 \mathrm{P}_{2}$ regulation directly affecting the lipid kinase, which we have termed the Mss4 nuclear transport cycle. Under normal conditions, Mss4 is phosphorylated by casein kinase I, resulting in its stable association with the plasma membrane. Regulated dephosphorylation of Mss4 may disrupt specific proteinprotein interactions required for plasma membrane localization and/or unmask the Mss4 NLS, which can then be recognized by the importin Kap123 for nuclear import. Nuclear export of Mss4 requires the essential protein Bcp1, which may potentially function as a component of the nuclear export machinery to transport Mss4 out of the nucleus to allow for $\mathrm{PI} 4,5 \mathrm{P}_{2}$ synthesis at the plasma membrane, required for normal actin cytoskeleton organization (Figure 9). Future studies will be required to determine if nuclear-cytoplasmic shuttling of lipid kinases represents a general mechanism for phospholipid regulation.

\section{Materials and methods}

\section{Strains and media}

Enzymes used for recombinant DNA techniques were purchased and used as recommended by the manufacturer. Standard recombinant DNA techniques and yeast genetics methods were performed, and the growth media used have been described elsewhere (Maniatis et al., 1982; Gaynor et al., 1994). Saccharomyces cerevisiae strains used in this study are listed in Table III. All gene disruptions were generated similarly, as described previously (Audhya and Emr, 2002). To generate temperaturesensitive mutant strains, temperature-sensitive alleles were transformed into heterozygous diploids prior to sporulation and tetrad dissection. All double mutant strains were generated as described previously, and disruptions were confirmed by PCR (Audhya and Emr, 2002). Integrated epitope tagging was performed as described previously (Longtine et al., 1998).

\section{Yeast library and plasmids}

The S.cerevisiae genomic library used for the suppressor screen was described previously (Stagljar et al., 1994). Generation of pRS415 MSS4$G F P$ was performed in two steps. First, MSS4 was chromosomally tagged with GFP. The C-terminal fragment of MSS4-GFP, including the $3^{\prime}$ $A D H 1$ terminator, was then amplified using PCR and subcloned into pRS415 MSS4 under its endogenous promoter. To generate a plasmid 
expressing $G F P-B C P 1, B C P 1$ was amplified using PCR and subcloned into pGO36 as described previously (Audhya et al., 2002). To generate a plasmid expressing Mss4-NLS-NES-GFP, the nuclear localization signal of Mss 4 was amplified by PCR and subcloned in-frame into pPS1372 as described previously (Taura et al., 1997). Strains expressing temperatureconditional alleles of mss4-GFP and $b c p l$ were generated similarly as described using error-prone PCR (Audhya et al., 2000). All point mutations were created similarly, using site-directed mutagenesis. To generate PSR-MSS4-GFP, nucleotides 4-81 of PSR1 were inserted immediately following the MSS4 start codon using PCR.

\section{Metabolic labeling, fractionation and immunoprecipitation}

Cell labeling, immunoprecipitations and fractionations were performed as described previously (Gaynor et al., 1994; Audhya et al., 2000). For ${ }^{32} \mathrm{P}-$ labeling, cells were grown in low-phosphate media to early log phase and labeled with $1 \mathrm{mCi}$ of ${ }^{32} \mathrm{P}$-labeled orthophosphate in the absence of phosphate. Treatment with shrimp alkaline phosphatase and immunoprecipitation with antiserum against GFP have been described previously (Rudge et al., 1998; Audhya and Emr, 2002).

\section{In vivo phosphoinositide labeling}

Analysis of phosphoinositide levels was performed as described previously (Audhya et al., 2000). Analysis of ${ }^{3} \mathrm{H}$-labeled glycerolphosphoinositols was performed by separation on a Beckman System Gold HPLC and quantified by liquid scintillation counting by a Packard online radiomatic detector

\section{Fluorescence microscopy}

All fluorescence images were observed using a Zeiss Axiovert S1002TV fluorescent microscope and subsequently processed using a Delta Vision deconvolution system. For DAPI staining, cells were briefly fixed and permeabilized in $3.7 \%$ formaldehyde containing $0.02 \%$ Triton X-100. For studies using leptomycin (Sigma), cells were treated as described previously (Neville and Rosbash, 1999). For actin localization, cells were fixed and stained with rhodamine-phalloidin (Molecular Probes) as described previously (Audhya et al., 2000).

\section{Acknowledgements}

We are grateful to Jeremy Thorner for his many useful suggestions on this manuscript. We also thank Pam Silver, Howard Riezman, Molly Fitzgerald-Hayes, Masayasu Nomura and Jeremy Thorner for generously providing us with plasmids and strains. We thank Chris Stefan and Beth Weaver for critically reading this manuscript, and Perla Arcaira for technical assistance. This work was partially supported by grant CA58689 from the National Institutes of Health (to S.D.E.). S.D.E. is an investigator of the Howard Hughes Medical Institute.

\section{References}

Audhya,A. and Emr,S.D. (2002) Stt4 PI 4-kinase localizes to the plasma membrane and functions in the Pkc1-mediated MAP kinase cascade. Dev. Cell, 2, 593-605.

Audhya,A., Foti,M. and Emr,S.D. (2000) Distinct roles for the yeast phosphatidylinositol 4-kinases, Stt4p and Pik1p, in secretion, cell growth and organelle membrane dynamics. Mol. Biol. Cell, 11, 26732689.

Berridge,M.J. and Irvine,R.F. (1984) Inositol trisphosphate, a novel second messenger in cellular signal transduction. Nature, 312, 315321.

Bevis,B.J., Hammond,A.T., Reinke,C.A. and Glick,B.S. (2002) De novo formation of transitional ER sites and Golgi structures in Pichia pastoris. Nat. Cell Biol., 4, 750-756.

Boronenkov,I.V., Loijens,J.C., Umeda,M. and Anderson,R.A. (1998) Phosphoinositide signaling pathways in nuclei are associated with nuclear speckles containing pre-mRNA processing factors. Mol. Biol. Cell, 9, 3547-3560.

Delley,P.A. and Hall,M.N. (1999) Cell wall stress depolarizes cell growth via hyperactivation of RHO1. J. Cell Biol., 147, 163-174.

Desrivières,S., Cooke,F.T., Parker,P.J. and Hall,M.N. (1998) MSS4, a phosphatidylinositol-4-phosphate 5-kinase required for organization of the actin cytoskeleton in Saccharomyces cerevisiae. J. Biol. Chem., 273, 15787-15793.

Dingwall,C. and Laskey,R.A. (1991) Nuclear targeting sequences-a consensus? Trends Biochem. Sci., 16, 478-481.
Ferrigno,P., Posas,F., Koepp,D., Saito,H. and Silver,P.A. (1998) Regulated nucleo/cytoplasmic exchange of HOG1 MAPK requires the importin beta homologs NMD5 and XPO1. EMBO J., 17, 56065614.

Friant,S., Zanolari,B. and Riezman,H. (2000) Increased protein kinase or decreased PP2A activity bypasses sphingoid base requirement in endocytosis. EMBO J., 19, 2834-2844.

Fruman,D.A., Meyers,R.E. and Cantley,L.C. (1998) Phosphoinositide kinases. Аnпи. Rev. Biochem., 67, 481-507.

Garcia-Bustos,J.F., Marini,F., Stevenson,I., Frei,C. and Hall,M.N. (1994) Pik1, an essential phosphatidylinositol 4-kinase associated with the yeast nucleus. EMBO J., 13, 2352-2361.

Gaynor,E.C., Heesen,S.T., Graham,T.R., Aebi,M. and Emr,S.D. (1994) Signal-mediated retrieval of a membrane protein from the Golgi to the ER in yeast. J. Cell Biol., 127, 653-665.

Harper,J.W. et al. (1995) Inhibition of cyclin-dependent kinases by $\mathrm{p} 21$. Mol. Biol. Cell, 6, 387-400.

Ho,Y. et al. (2002) Systematic identification of protein complexes in Saccharomyces cerevisiae by mass spectrometry. Nature, $\mathbf{4 1 5}, 180$ 183.

Homma,K., Terui,S., Minemura,M., Qadota,H., Anraku,Y., Kanaho,Y. and Ohya,Y. (1998) Phosphatidylinositol-4-phosphate 5-kinase localized on the plasma membrane is essential for yeast cell morphogenesis. J. Biol. Chem., 273, 15779-15786.

Kaffman,A., Rank,N.M., O'Neill,E.M., Huang,L.S. and O'Shea,E.K. (1998) The receptor Msn5 exports the phosphorylated transcription factor Pho4 out of the nucleus. Nature, 396, 482-486.

Liu,J., Yuan,Y., Huan,J. and Shen,Z. (2001) Inhibition of breast and brain cancer cell growth by BCCIP $\alpha$, an evolutionarily conserved nuclear protein that interacts with BRCA2. Oncogene, 20, 336-345.

Longtine,M.S., McKenzie,A., Demarini,D.J., Shah,N.G., Wach,A., Brachat,A., Philippsen,P. and Pringle,J.R. (1998) Additional modules for versatile and economical PCR-based gene deletion and modification in Saccharomyces cerevisiae. Yeast, 14, 953-961.

Maniatis,T., Fritsch,E.F. and Sambrook,J. (1982) Molecular Cloning: A Laboratory Manual. Cold Spring Harbor Press, Cold Spring Harbor, NY.

Martin,T.F. (1998) Phosphoinositide lipids as signaling molecules: common themes for signal transduction, cytoskeletal regulation and membrane trafficking. Annu. Rev. Cell Dev. Biol., 14, 231-264.

Mattaj,I.W. and Englmeier,L. (1998) Nucleocytoplasmic transport: the soluble phase. Annu. Rev. Biochem., 67, 265-306.

Meng,X., Liu,J. and Shen,Z. (2003) Genomic structure of the human BCCIP gene and its expression in cancer. Gene, 302, 139-146.

Neville,M. and Rosbash,M. (1999) The NES-Crm1p export pathway is not a major mRNA export route in Saccharomyces cerevisiae. EMBO J., 18, 3746-3756.

O'Neill,E.M., Kaffman,A., Jolly,E.R. and O'Shea,E.K. (1996) Regulation of PHO4 nuclear localization by the PHO80-PHO85 cyclin-CDK complex. Science, 271, 209-212.

Ono,T., Kitaura,H., Ugai,H., Murata,T., Yokoyama,K.K., IguchiAriga,S.M. and Ariga,H. (2000) TOK-1, a novel p21Cip1-binding protein that cooperatively enhances p21-dependent inhibitory activity toward CDK2 kinase. J. Biol. Chem., 275, 31145-31154

Park,S.J., Itoh,T. and Takenawa,T. (2001) Phosphatidylinositol 4phosphate 5-kinase type $\mathrm{I}$ is regulated through phosphorylation response by extracellular stimuli. J. Biol. Chem., 276, 4781-4787.

Robinson,J.S., Klionsky,D.J., Banta,L.M. and Emr,S.D. (1988) Protein sorting in Saccharomyces cerevisiae: isolation of mutants defective in the delivery and sorting of multiple vacuolar hydrolases. Mol. Cell. Biol., 8, 4936-4948.

Rout,M.P., Blobel,G. and Aitchison,J.D. (1997) A distinct nuclear import pathway used by ribosomal proteins. Cell, 89, 715-725.

Rudge,S.A., Morris,A.J. and Engebrecht,J. (1998) Relocalization of phospholipase D activity mediates membrane formation during meiosis. J. Cell Biol., 140, 81-90.

Ryan,K.J. and Wente,S.R. (2000) The nuclear pore complex: a protein machine bridging the nucleus and cytoplasm. Curr. Opin. Cell Biol., 12, 361-371.

Siniossoglou,S., Hurt,E.C. and Pelham,H.R. (2000) Psr1p/Psr2p, two plasma membrane phosphatases with an essential DXDX $(\mathrm{T} / \mathrm{V})$ motif required for sodium stress response in yeast. J. Biol. Chem., 275, 19352-19360.

Srinivasan,S., Seaman,M., Nemoto,Y., Daniell, L, Suchy,S.F., Emr,S.D., De Camilli, P and Nussbaum,R. (1997) Disruption of three phosphatidylinositol-polyphosphate 5-phosphatase genes from Saccharomyces cerevisiae results in pleiotropic abnormalities of 


\section{A.Audhya and S.D.Emr}

vacuole morphology, cell shape and osmohomeostasis. Eur. J. Cell Biol., 74, 350-360.

Stade,K., Ford,C.S., Guthrie,C. and Weis,K. (1997) Exportin 1 (Crm1p) is an essential nuclear export factor. Cell, 90, 1041-1050.

Stage-Zimmermann,T., Schmidt,U. and Silver,P.A. (2000) Factors affecting nuclear export of the 60S ribosomal subunit in vivo. Mol. Biol. Cell, 11, 3777-3789.

Stagljar,I., te Hessen,S. and Aebi,M. (1994) New phenotype of mutations deficient in glucosylation of the lipid-linked oligosaccharide: cloning of the ALG8 locus. Proc. Natl Acad. Sci. USA, 91, 5977-5981.

Stefan,C.J., Audhya,A. and Emr,S.D. (2002) The yeast synaptojanin-like proteins control the cellular distribution of phosphatidylinositol $(4,5)-$ bisphosphate. Mol. Biol. Cell, 13, 542-557.

Stolz,L.E., Huynh,C.V., Thorner,J. and York,J.D. (1998) Identification and characterization of an essential family of inositol polyphosphate 5-phosphatases (INP51, INP52 and INP53 gene products) in the yeast Saccharomyces cerevisiae. Genetics, 148, 1715-1729.

Stommel,J.M., Marchenko,N.D., Jimenez,G.S., Moll,U.M., Hope,T.J. and Wahl,G.M. (1999) A leucine-rich nuclear export signal in the p53 tetramerization domain: regulation of subcellular localization and p53 activity by NES masking. EMBO J., 18, 1660-1672.

Takenawa,T. and Itoh,T. (2001) Phosphoinositides, key molecules for regulation of actin cytoskeletal organization and membrane traffic from the plasma membrane. Biochim. Biophys. Acta., 1533, 190-206.

Taura,T., Schlenstedt,G. and Silver,P.A. (1997) Yrb2p is a nuclear protein that interacts with Prp20p, a yeast Rcc1 homologue. J. Biol. Chem., 272, 31877-31884.

Xiao,Z., McGrew,J.T., Schroeder,A.J. and Fitzgerald-Hayes,M. (1993) CSE1 and CSE2, two new genes required for accurate mitotic chromosome segregation in Saccharomyces cerevisiae. Mol. Cell Biol., 13, 4691-4702.

Yoshida,S., Ohya,Y., Nakano,A. and Anraku,Y. (1994) Genetic interactions among genes involved in the STT4-PKC1 pathway of Saccharomyces cerevisiae. Mol. Gen. Genet., 242, 631-640.

Received April 15, 2003; revised June 23, 2003; accepted June 25, 2003 